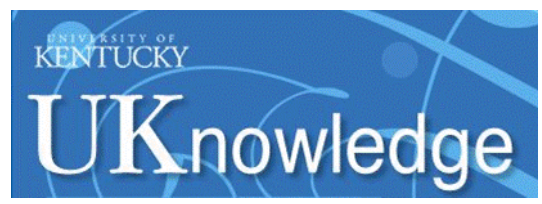

University of Kentucky

UKnowledge

Winter 2019

\title{
Maternal Work Hours and Childhood Obesity: Evidence Using Instrumental Variables Related to Sibling School Eligibility
}

Charles J. Courtemanche

University of Kentucky, courtemanche@uky.edu

Rusty Tchernis

Georgia State University

Xilin Zhou

Georgia State University

Follow this and additional works at: https://uknowledge.uky.edu/economics_facpub

Part of the Economics Commons, and the Public Health Commons

Right click to open a feedback form in a new tab to let us know how this document benefits you.

\section{Repository Citation}

Courtemanche, Charles J.; Tchernis, Rusty; and Zhou, Xilin, "Maternal Work Hours and Childhood Obesity: Evidence Using Instrumental Variables Related to Sibling School Eligibility" (2019). Economics Faculty Publications. 8.

https://uknowledge.uky.edu/economics_facpub/8

This Article is brought to you for free and open access by the Economics at UKnowledge. It has been accepted for inclusion in Economics Faculty Publications by an authorized administrator of UKnowledge. For more information, please contact UKnowledge@lsv.uky.edu. 
Maternal Work Hours and Childhood Obesity: Evidence Using Instrumental Variables Related to Sibling School Eligibility

\section{Digital Object Identifier (DOI)}

https://doi.org/10.1086/705609

Notes/Citation Information

Published in Journal of Human Capital, v. 13, no. 4.

(C) 2019 by The University of Chicago. All rights reserved.

The copyright holder has granted the permission to post the article here. 


\section{Maternal Work Hours and Childhood Obesity: Evidence Using Instrumental Variables Related to Sibling School Eligibility}

\section{Charles Courtemanche}

University of Kentucky, National Bureau of Economic Research, and Institute for the Study of Labor (IZA)

Rusty Tchernis

Georgia State University, National Bureau of Economic Research, and Institute for the Study of Labor (IZA)

Xilin Zhou

Georgia State University

This study exploits plausibly exogenous variation derived from the youngest sibling's school eligibility to estimate the effects of maternal work on the weight outcomes of older children. We first show that mothers' work hours increase gradually along both the extensive and intensive margins as the age of the youngest child rises, whereas mothers' spouses' work hours do not appear to be responsive. We develop an instrumental-variables model that shows that mothers' work hours lead to larger increases in children's body mass index z-scores and probabilities of being overweight/obese than those identified in previous studies. Subsample analyses find that the effects are concentrated among advantaged households.

\section{Introduction}

The statistics on childhood obesity in the United States are alarming. From 1971 to 2014, the childhood obesity rate rose from 5 percent to

We thank the editors Jane Fruehwirth and Isaac Ehrlich, two anonymous referees, Rachana Bhatt, Barry Hirsh, Darren Lubotsky, Sara Markowitz, James Marton, Kurt Schnier, and seminar participants at the Southern Economic Association Annual Meeting and the Western Economics Association Annual Conference for helpful comments. We also thank Patricia Anderson for sharing parameter estimates from Anderson et al. (2003). This research used restricted data from the Bureau of Labor Statistics (BLS). The views expressed in this paper do not reflect those of the BLS. Any errors are ours.

Electronically Published October 30, 2019.

[ Journal of Human Capital, 2019, vol. 13, no. 4]

(c) 2019 by The University of Chicago. All rights reserved. 1932-8575/2019/1304-0002\$10.00 
17 percent (Fryar, Carroll, and Ogden 2016). The increase is especially notable among school-aged children, as the obesity rate quadrupled for children aged 6-11 and tripled for those aged 12-19, compared to doubling for those aged 2-5 (Fryar et al. 2016). The prevalence of obesity among children is considered a major public health concern because of its immediate and long-term effects on health and well-being. According to the Centers for Disease Control and Prevention (CDC), obese children are at a higher risk of developing cardiovascular disease, prediabetes, bone and joint problems, sleep apnea, and psychological problems. Obese children are also likely to grow up as obese adults and therefore face the risk of adult obesity-related health problems (https://www.cdc.gov/obesity/child hood/causes.html). As of 2005, the annual medical cost of treating child hood obesity was $\$ 14.1$ billion for prescription drugs, emergency room, and outpatient visit costs (Trasande and Chatterjee 2009), plus $\$ 237.6$ million for inpatient costs (Trasande et al. 2009). Among adults, obesity leads to an estimated $\$ 210$ billion of annual medical expenses, as well as indirect costs such as unfavorable labor market outcomes (Cawley 2004; Cawley and Meyerhoefer 2012).

Another remarkable trend in the second half of the twentieth century was increased employment among women. From 1960 to 2013, the labor force participation rate (LFPR) of women 16 years old and older increased from 38 percent to 57 percent. The male LFPR fell from 83 percent to 70 percent at the same time, but the overall LFPR combining both genders still rose, from 59 percent to 63 percent. Similar trends were observed for those with children under age 18 in the household. Between 1970 and 2013, the LFPR increased from 42 percent to 70 percent among mothers and declined from 97 percent to 93 percent among fathers. ${ }^{1}$

The concurrent nature of these trends in LFPR and childhood obesity has led researchers to ask whether a causal connection is possible. Some important changes occur when mothers increase their labor supply that could influence children's weight. First, their children have less supervision and watch more television than the children of stay-at-home mothers (Fertig, Glomm, and Tchernis 2009; Cawley and Liu 2012; Ziol-Guest, Dunifon, and Kalil 2013). Second, working mothers spend less time on cooking than other mothers, and their children eat more away-from-home meals (Cawley and Liu 2012). Next, more market work increases household income, which could affect children's weight in either direction. The loosening of the budget constraint could either mean more acrossthe-board food purchases or a switch away from cheap processed foods toward more expensive, healthier options. Finally, to the extent that fathers reduce work hours in response to mothers entering the labor force, this could counteract whatever effects might otherwise occur. Indeed, Cawley and Liu (2012) find some evidence of offsetting time use behaviors by fathers, but it is not nearly enough to offset the changes by mothers.

1 These numbers are authors' calculations from the Current Population Surveys. 
Several studies document a modest positive relationship between maternal employment and children's weight. Anderson, Butcher, and Levine (2003) find that an extra 10 hours worked per week during weeks worked by a mother are associated with around a 1 percentage point increase in the probability of a 3-11-year-old child being obese. The impact is largest for high-socioeconomic-status children. Similar magnitudes are obtained by Ruhm (2008), Courtemanche (2009), and Ziol-Guest et al. (2013). Fertig et al. (2009) estimate that a 10 percent increase in a mother's work hours is associated with approximately a 1.6 percentage point rise in the probability that her child is obese. Liu et al. (2009) find that full-time maternal employment raises a child's body mass index (BMI) by about half a unit and probability of being obese by 12 percent. Morrissey, Dunifon, and Kalil (2011) and Morrissey (2012) estimate that every survey period in which a mother is employed increases her child's BMI $z$-score by 0.02 and 0.03 , respectively.

Such analyses, however, are complicated by the endogeneity of maternal employment. A mother's unobserved characteristics likely affect both her labor supply and her child care decisions. For instance, greater intelligence might increase both the likelihood of a mother participating in the labor force and her ability to develop effective strategies to prevent her children from becoming obese. Similarly, highly conscientious mothers could be more likely than others to both work outside the home and closely monitor their children's behaviors. In either case, associational estimates may underestimate the effect of maternal employment on childhood obesity, potentially explaining the small magnitudes obtained by prior studies. On the other hand, if entering the labor market reflects an underlying preference for income versus family time, associational estimates could be overstated. Reverse causality is another possible concern. Having a child with health problems may cause a mother to either exit the labor force to care for the child or enter the labor force to obtain health insurance or extra income. ${ }^{2}$

To address these endogeneity concerns, this study implements an IV strategy based on the idea that the opportunity cost of working is substantially reduced when one's youngest child is attending school. Several studies have established that mothers increase labor supply when their

\footnotetext{
${ }^{2}$ Some of the papers in the literature have implemented panel data methods to control for unobserved heterogeneity (Anderson et al. 2003; Courtemanche 2009; Miller 2011; Morrissey et al. 2011), but these methods do not account for time-varying sources of bias or reverse causality. Anderson et al. (2003) also estimated an instrumental-variables (IV) specification, using as instruments state-level variables including unemployment rate, child care regulations, wages of child care workers, welfare benefit levels, and the status of welfare reform in the state. However, these instruments were relatively weak in terms of their predictive power on maternal work. They also relied on questionable exclusion restrictions, as the instruments could influence childhood obesity through pathways besides maternal work. For instance, unemployment rate and the generosity of a state's welfare program could be associated with changes in household disposable income or wealth even if mothers' work hours do not change, and this in turn could affect children's weight.
} 
youngest child becomes eligible for or enrolls in public school (Gelbach 2002; Cascio 2009; Fitzpatrick 2010, 2012; Morrill 2011). Morrill (2011) uses the youngest child's kindergarten eligibility as an instrument to show that maternal employment increases the probability of older children in the household experiencing hospitalizations, asthma episodes, and injuries/ poisonings. We utilize a related strategy to examine the effect of mothers' work on childhood obesity.

We begin by investigating, both semiparametrically and parametrically, how the age of the youngest child relative to the kindergarten eligibility cutoff influences parental work. Data come from the National Longitudinal Survey of Youth 1979 cohort (NLSY79). We find that mothers' work hours gradually increase as the age of the youngest child rises, as opposed to jumping discontinuously when the child becomes eligible for kindergarten. This is consistent with graphical evidence provided by Morrill (2011), using data from the NLSY, and Lubotsky and Qureshi (2018), using data from the American Time Use Survey, American Community Survey, and Panel Survey of Income Dynamics. The effect on mothers' work occurs along both the extensive margin (probability of working) and the intensive margin (work hours conditional on working). In contrast, mothers' spouses' work hours do not exhibit any clear responsiveness to youngest child's age, again consistent with the findings of Lubotsky and Qureshi (2018). Our estimates generally remain similar across subgroups stratified by education, race/ethnicity, marital status, and an index of "advantage" based on all these characteristics.

Next, we leverage these insights to develop an IV model in which plausibly exogenous variation in the youngest child's age relative to kindergarten eligibility identifies the impact of maternal employment on the weight of older children in the household. We show that greater mothers' work hours lead to statistically significant increases in children's BMI z-score and probabilities of being overweight and obese that are much larger than those observed in the associational literature. While the estimates are imprecise, we are nonetheless able to rule out the consistency of the ordinary least squares (OLS) estimator in most specifications. The results imply that the increase in maternal employment has been an important contributor to the rise in childhood obesity. Next, we conduct subsample analyses and show that the effect of parental work hours on children's weight is concentrated among relatively advantaged households. Finally, falsification tests using health-behavior-related outcomes that should not be affected by parental work provide evidence to support our model's identifying assumptions.

Our study's primary contribution is to provide the first application of a youngest-sibling's-age-based IV strategy to study the impact of maternal work on a chronic health condition (obesity), as opposed to the acute conditions studied by Morrill (2011). Since chronic conditions represent capital stocks, one might expect them to be less responsive than acute episodes to changes in inputs to the health production function. Our 
finding that short-run changes in parental work can still have large effects on children's weight is therefore noteworthy. As a secondary contribution, we offer new insights as to how parents' labor supply changes with the age of their youngest child by being the first to use semiparametric regressions and to distinguish between the extensive and intensive margins of work when studying the topic.

\section{Data}

Data come from the restricted version of the NLSY79. The original sample of the NLSY79 contains 12,682 individuals, half male and half female, who were between the ages of 14 and 21 in 1979. These individuals were followed annually from 1979 to 1994 and every two years thereafter. Starting in 1986, a supplemental survey, the NLSY79 Child and Young Adult (NLSY79CYA), which includes assessments of all biological children of the female participants, was conducted biannually. Information was collected from either the mother or the child, and it can be linked to the main NLSY79 through the mother's identifier. ${ }^{3}$ We use the paired motherchildren records from all biannual waves from 1986 to 2010.

There are three outcomes of interest, BMI $z$-score and indicators for overweight and obesity, all of which are constructed on the basis of children's BMI. ${ }^{4}$ BMI is a commonly used proxy for body fat in adults. However, it is not a proper measure for children, because their healthy weight range varies by age and sex. Therefore, for children, the CDC suggests using BMI $z$-score, a standardized measure of BMI using age- and genderspecific BMI distributions from the 2000 growth chart (National Center for Health Statistics 2002). The other two outcomes are also computed according to the 2000 growth chart. If a child's BMI is above the 85th (95th) percentile of the BMI distribution of the corresponding reference population, the child is considered overweight (obese).

Mothers' and mothers' spouse's employment variables are fraction of weeks worked in the past year, hours worked per week in weeks worked in the past year (undefined if no work weeks), and hours worked per week over all weeks in the past year (zeros assigned in weeks not worked). The first of these variables therefore reflects the extensive margin of employment, the second reflects the intensive margin, and the third reflects overall work, accounting for both the extensive and intensive margins.

Youngest child's age relative to kindergarten eligibility is defined as the difference, measured in number of weeks divided by 52 , between the youngest child's age (in weeks) and the age at which she would become

${ }^{3}$ Before 1994, a mother reported information for all her children regardless of the age of children. After 1994, children above 15 years of age answered interview questions by themselves.

${ }^{4} \mathrm{BMI}$ is calculated as weight in kilograms divided by height in meters squared $\left(\mathrm{kg} / \mathrm{m}^{2}\right)$. 
eligible for kindergarten (in weeks). Functionally, then, it is the number of years away from eligibility, with fractions allowed. Consider two children born on September 23, 1990, in Ohio and Georgia, where eligibility cutoffs are September 30 and September 1, respectively. In Ohio, the child would qualify to attend school in 1995 , because she will be 5 years old by the cutoff date, but in Georgia she would have to wait until 1996. Thus, if the interviews were conducted on October 15, 1995, the relative age in weeks of the child in Ohio would be 2 weeks, while that of the child in Georgia would be -46 weeks. We then divide by 52 to convert these to relative ages in years of 0.038 and -0.88 , respectively. ${ }^{5}$

We also utilize the extensive information available in the NLSY79 and NLSY79CYA to include a detailed array of control variables. The first set of control variables is for demographic characteristics. The demographic variables taken from the NLSY79, which pertain to the mother, are race/ ethnicity (Hispanic and non-Hispanic black, with other as the reference group), family size, age in years and its square, and an indicator for married and living with the spouse. Demographic variables from the NLSY79CYA, which pertain to the focal child, are an indicator for gender, age in months, and an indicator for close child-father attachment (equals one if the biological father lives in the household, biological father lives within 10 miles, or child has seen biological father at least once a week in the past year).

The second set of control variables relates to parents' human capital. These variables, which all come from the NLSY79, are mother's Armed Forces Qualifying Test (AFQT) score and both mother's and mother's spouse's education (high school graduate, some college, and college degree or greater, with less than high school degree being the reference group). We do not control for household income, because this is one of the pathways through which parental work may affect children's weight. Nonetheless, results remain very similar if we include it.

The third set of control variables is named "child's health." It includes four variables from the NLSYCYA: whether the child had a high birth weight (>8.8 pounds) ${ }^{6}$ whether the child was breast-fed, and whether height or weight is self-reported. ${ }^{7}$ The latter two variables are included

\footnotetext{
${ }^{5}$ States' school year cutoff dates come from Evans, Morrill, and Parente (2010). Some states do not have a standard cutoff date for school year. Following Morrill (2011), we assume that September 1 is the cutoff for these states. We acknowledge the possibility for additional measurement error from school start dates (which we do not observe) not exactly matching the state's cutoff dates. For instance, in the Ohio example, if the child's particular school starts on September 1, we might ideally like to code her relative age as 6 weeks rather than 2. In practice, such differences are so small that there is little reason to expect them to affect our conclusions. The far more consequential policy variation is the one we account for, which is that children with the same birthday can have relative ages nearly a full year apart because of different state cutoffs.

6 The threshold of high birth weight can be found at http://www.cdc.gov/pednss/what _is/pednss_health_indicators.htm.

7 The interview questions concerning the measurements of height and weight changed frequently during the research period. There were only two modes at the beginning: mother report and interviewer measure. The questions evolved gradually, and eventually there were
} 
because self-reported data on height and weight usually suffer from systematic reporting error that leads to underestimation of the prevalence of obesity (Goodman, Hinden, and Khandelwal 2000; Kuczmarski, Kuczmarski, and Najjar 2001; Courtemanche, Pinkston, and Stewart 2015).

The regression sample is restricted to children who meet three criteria: (1) they are 7-17 years old, (2) they have at least one younger sibling, and (3) their youngest sibling's schooling eligibility changed during the sample period. The first restriction ensures that school eligibility does not change for the sample children. As discussed above, this eliminates the obvious concern that one's own school eligibility could affect one's own weight for reasons other than maternal employment. The second restriction is necessary for the use of IV. The third restriction is used to eliminate those whose mothers never receive the IV-induced treatment. ${ }^{8}$

The resulting sample includes 13,332 observations for 3,438 children of 2,220 mothers. Table 1 presents descriptive statistics for this merged, child-level data set, with all estimates weighted by the children's sampling weights. The average BMI $z$-score is 0.27 , and 26 percent of the children are overweight, while 12 percent of them are obese. On average, mothers worked 66 percent of weeks in the past year, while spouses worked 93 percent. In weeks worked, average work hours were 35 for mothers and 47 for spouses. Across all weeks, including zeros for weeks not worked, mothers worked an average of 24 hours, compared to 43 for spouses.

\section{Effect of Youngest Child's Kindergarten Eligibility on Parents' Work}

Our first objective is to identify the effect of the youngest child's age relative to the kindergarten eligibility cutoff on parents' work hours. Such an analysis will inform the design of the IV model for childhood obesity. Since the dependent variables in this section are measured at the parent rather than the child level, we use a version of the data set that is at the mother-by-year level and includes only the control variables from the NLSY79, omitting those from the NLSY79CYA. This decision is not consequential for the results, as the first stage of the IV model in the next

\footnotetext{
four options: mother report, child report, interviewer measure, and others. In addition, young adults above age 15 have been interviewed independently since 1996. Their height and weight data are all self-reported. To simplify the classifications, I create an indicator that represents all modes except interviewer measure for height and weight data and call it "selfreported mode."

8 Other steps to improve data quality include dropping children with extreme BMIs (zscore exceeding \pm 5 ), children who have shrinking height since the previous interview, children who do not live with their mothers, female children who are pregnant or ever have given birth, and those whose mothers do not have any valid employment data. Only 1 percent of mothers lack any employment data, and the results remain virtually identical if we include them and code them as always having zero work hours.
} 
TABLE 1

Summary Statistics for Parents and their Children Aged 7-17 Years Old

\begin{tabular}{|c|c|c|}
\hline Variables & Source & $\begin{array}{c}\text { Mean } \\
\text { (Standard Deviation) }\end{array}$ \\
\hline \multicolumn{3}{|l|}{ Dependent variables: } \\
\hline BMI $z$-score & NLSY79CYA & $.274(1.152)$ \\
\hline Overweight & NLSY79CYA & $.264(.441)$ \\
\hline Obesity & NLSY79CYA & $.117(.321)$ \\
\hline \multicolumn{3}{|l|}{ Work variables: } \\
\hline Mother's fraction of weeks worked in past year & NLSY79 & $.655(.431)$ \\
\hline $\begin{array}{l}\text { Mother's hours worked/week (in 10s) in weeks } \\
\text { worked in past year (undefined if no work weeks) }\end{array}$ & NLSY79 & $3.540(1.401)$ \\
\hline $\begin{array}{l}\text { Mother's hours worked/week (in } 10 \text { s) over all } \\
\text { weeks in past year ( } 0 \text { if no work weeks) }\end{array}$ & NLSY79 & $2.352(1.906)$ \\
\hline $\begin{array}{l}\text { Spouse's fraction of weeks worked in past year } \\
\text { (undefined if no spouse) }\end{array}$ & NLSY79 & $.926(.212)$ \\
\hline $\begin{array}{l}\text { Spouse's hours worked/week (in 10s) in weeks } \\
\text { worked in past year (undefined if no spouse or } \\
\text { no work weeks) }\end{array}$ & NLSY79 & $4.657(1.117)$ \\
\hline $\begin{array}{l}\text { Spouse's hours worked/week (in 10s) over all } \\
\text { weeks in past year (undefined if no spouse, } \\
0 \text { if no work weeks) }\end{array}$ & NLSY79 & $4.315(1.487)$ \\
\hline \multicolumn{3}{|l|}{ Youngest sibling age variable: } \\
\hline $\begin{array}{l}\text { Relative age (in years) to kindergarten } \\
\text { eligibility cutoff }\end{array}$ & NLSY79 & $1.035(3.638)$ \\
\hline \multicolumn{3}{|l|}{ Demographic control variables: } \\
\hline Mother is Hispanic & NLSY79 & $.076(.266)$ \\
\hline Mother is non-Hispanic black & NLSY79 & $.153(.360)$ \\
\hline Family size & NLSY79 & $4.854(1.240)$ \\
\hline Mother's age in years & NLSY79 & $36.470(5.211)$ \\
\hline Spouse's age in years ( 0 if no spouse) & NLSY79 & $28.289(18.186)$ \\
\hline Mother is married and lives with spouse & NLSY79 & $.724(.447)$ \\
\hline Child is female & NLSY79CYA & $.487(.500)$ \\
\hline Child's age in months & NLSY79CYA & $149.400(37.134)$ \\
\hline Attachment to biological father & NLSY79CYA & $.775(.418)$ \\
\hline \multicolumn{3}{|l|}{ Human capital control variables: } \\
\hline Mother's AFQT score (2006 standardization) & NLSY79 & $48.353(28.423)$ \\
\hline Mother's education: high school graduate & NLSY79 & $.445(.497)$ \\
\hline Mother's education: some college & NLSY79 & $.237(.425)$ \\
\hline Mother's education: college degree or higher & NLSY79 & $.211(.408)$ \\
\hline Spouse's education: high school graduate & & \\
\hline (0 if no spouse) & NLSY79 & $.287(.453)$ \\
\hline Spouse's education: some college ( 0 if no spouse) & NLSY79 & $.143(.350)$ \\
\hline Spouse's education: college degree ( 0 if no spouse) & NLSY79 & $.089(.285)$ \\
\hline \multicolumn{3}{|c|}{ Child's health control variables: } \\
\hline High birth weight & NLSY79CYA & $.107(.309)$ \\
\hline Breast-fed & NLSY79CYA & $.575(.494)$ \\
\hline Height is self-reported & NLSY79CYA & $.507(.500)$ \\
\hline Weight is self-reported & NLSY79CYA & $.519(.500)$ \\
\hline
\end{tabular}

Note.-Estimates are weighted by children's sampling weights.

section uses child-level data, includes the controls for the focal child, and leads to the same conclusion. In the analyses of spouse's work outcomes, we restrict the sample to mothers with spouses. Regressions for the intensivemargin outcomes (mother's/mother's spouse's hours worked in weeks worked) drop mothers/mothers' spouses with no work weeks. 


\section{A. Semiparametric Regressions}

We begin by estimating semiparametric models that allow for a flexible functional form when modeling the relationship between youngest child's relative age and parents' work. The regressions take the form

$$
\operatorname{WORK}_{i t}=\beta_{0}+f\left(\operatorname{RELAGE}_{i t}\right)+\boldsymbol{\beta}_{1} \boldsymbol{X}_{i t}+\tau_{t}+\varepsilon_{i t},
$$

where WORK $_{i t}$ is the measure of work for parent $i$ in year $t$ and RELAGE is the youngest child's age relative to the eligibility cutoff (in years, with fractions allowed). We use Robinson's (1988) double residual estimator to model the expected value of the outcome at every point on the distribution of $\mathrm{RELAGE}_{i t}{ }^{9}$ Here, $\boldsymbol{X}_{i t}$ contains the demographic and human capital control variables listed in table $1, \tau_{t}$ is a year fixed effect, and $\varepsilon_{i t}$ is the error term.

We control for unobserved heterogeneity by adding the baseline value of the work outcome to the vector $\boldsymbol{X}_{i t}{ }^{10}$ This value is measured in the period immediately preceding the mother's first entry into the sample. Recall that mothers make their first entry into the sample when one of their older children reaches 7 years old; therefore, the baseline value is usually from when this older child is $5-6$ years old. If that particular value is missing, we use the preceding period (e.g., when the older child is $3-$ 4 years old).

Figure 1 displays the results with mother's hours worked per week across all weeks (including those not worked) as the dependent variable. The graph shows how the predicted value of work hours changes across the distribution of youngest child's relative age, along with a scatter plot. We see that a mother's predicted work rises gradually as her youngest child grows older, starting at about 15 hours per week when the child is a newborn and eventually reaching over 30 hours per week by eighth grade. The rate of change slows only slightly as relative age increases. In contrast, if the increase in maternal work occurred suddenly once her youngest child became eligible for school, we would expect a flat line for relative age less than 0 , a linear increase between relative ages of 0 and 1 year (because the work hour variable is an average over the preceding year rather than a snapshot of the present week), and a flat line for relative age above 1 year. We do not observe anything close to that pattern. Figures A1 and A2 (figs. A1-A4 are available online) document similar patterns for the other

\footnotetext{
${ }^{9}$ We refer the reader to Robinson (1988) for the details of the estimation method. We implement the estimator by using the Stata program semipar by Verardi and Debarsy (2012).

${ }^{10}$ We control for baseline work rather than including mother fixed effects because the latter would lead to extreme multicollinearity, as the relative-age variable would be almost completely explained by the year and mother fixed effects. The collinearity is not perfect because there is some additional variation in youngest child's age relative to kindergarten eligibility coming from differences in state eligibility laws, new births among mothers (which reset the age of the youngest child), and the fact that relative age is measured in weeks rather than years. In practice, however, these additional sources of variation are insufficient to estimate the coefficients of interest with meaningful precision.
} 


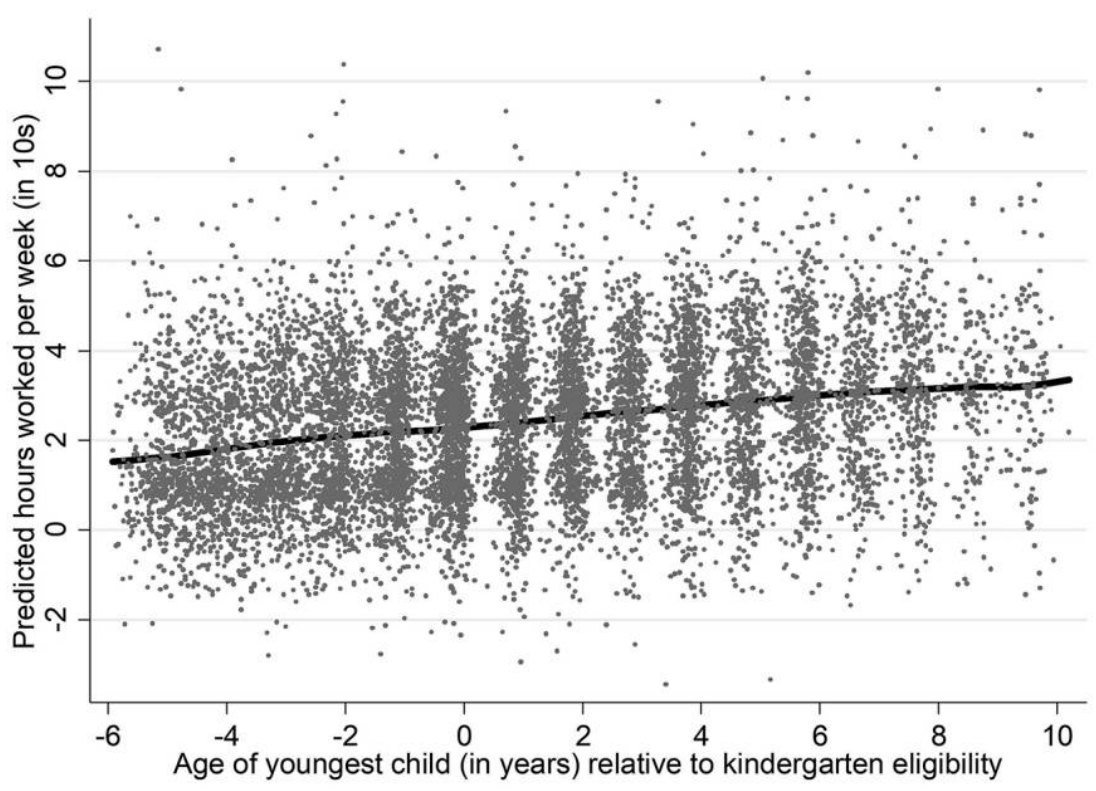

Figure 1.-Youngest child's age and mother's hours worked per week over all weeks. Robinson's semiparametric estimator, with Epanechnikov kernel, is used. Demographic, human capital, and baseline work controls are included. The demographic controls are mother is Hispanic, mother is non-Hispanic black, family size, mother's age in years, spouse's age in years ( 0 if no spouse), mother is married and lives with spouse, child is female, child's age in months, and attachment to biological father. The human capital controls are mother's AFQT score (2006 standardization), mother's education (high school graduate, some college, and college degree or higher), and spouse's education (high school graduate, some college, and college degree or higher; all are 0 if no spouse). Observations are weighted by mother's sampling weights.

two mothers' work outcomes: proportion of weeks worked and hours worked per week in weeks worked. The increase in work hours is therefore gradual, rather than sudden, and occurs along both the extensive and intensive margins.

Figure 2 shows the results from a similar graph for mother's spouse's hours worked per week across all weeks. We observe almost a straight horizontal line on 40 hours, indicating no meaningful increase in spouses' labor supply as the youngest child's age relative to kindergarten rises. Figures A3 and A4 show similarly flat curves for spouse's proportion of weeks worked and hours worked in weeks worked. ${ }^{11}$

11 One possible concern with the spouse's work analyses is compositional changes in the sample of married mothers as the youngest child gets older. To help rule out this concern, we conduct auxiliary analyses showing that, conditional on the mother's demographic and human capital controls, youngest child's relative age is not significantly associated with the probabilities that the mother is married (coefficient estimate $0.003, p=.261$ ), living with the child's father $(-0.004, p=.156)$, or living with the child's father with the sample restricted to married mothers $(-0.001, p=.595)$. 


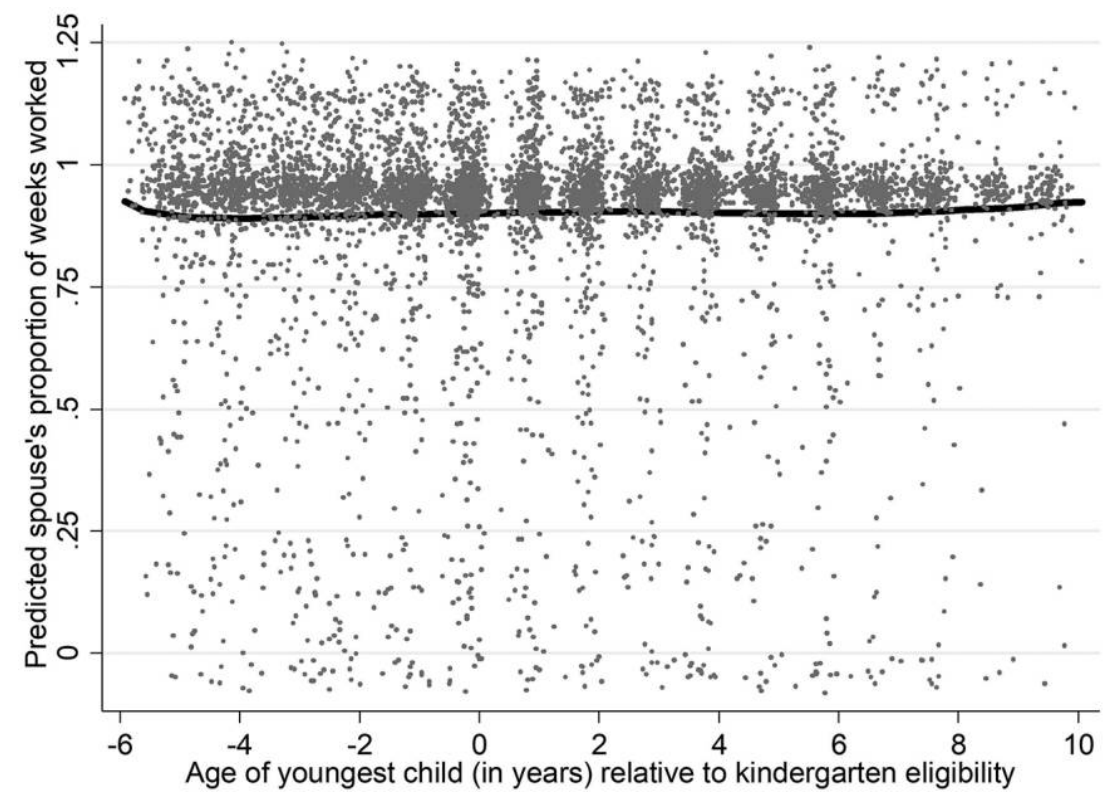

Figure 2.-Youngest child's age and mother's spouse's proportion of weeks worked. Robinson's semiparametric estimator, with Epanechnikov kernel, is used. The sample excludes mothers without spouses. Demographic, human capital, and baseline work controls are included. The demographic controls are mother is Hispanic, mother is non-Hispanic black, family size, mother's age in years, spouse's age in years, mother is married and lives with spouse, child is female, child's age in months, and attachment to biological father. The human capital controls are mother's AFQT score (2006 standardization), mother's education (high school graduate, some college, and college degree or higher), and spouse's education (high school graduate, some college, and college degree or higher). Observations are weighted by mother's sampling weights.

\section{B. Parametric Regressions}

We next examine whether the conclusions reached above persist when estimating parametric, rather than semiparametric, models. The semiparametric results above indicate that there is little reason to consider beyond a quadratic specification, as the diminishing marginal effect of youngest child's age on mother's work essentially follows a quadratic shape. We therefore estimate, for all six work outcomes, versions of equation (1) that use linear and quadratic functional forms for youngest child's relative age.

Table 2 reports the results for the mother's work outcomes. To evaluate robustness, we start with a model with only demographic controls in column 1, then add human capital controls in column 2, and finally add the baseline work outcome in column 3. In panel A, we see that mothers' weeks worked rise with youngest child's age relative to kindergarten eligibility. When we use a quadratic functional form, both relative age and its square are significant in all three regressions, with the pattern of signs indicating a positive but diminishing marginal effect. Panel B shows the 
TABLE 2

Effects of Youngest Child's Relative Age to Kindergarten on Mother's Work

\begin{tabular}{|c|c|c|c|}
\hline & $\begin{array}{c}\text { Demographic } \\
\text { Controls } \\
(1)\end{array}$ & $\begin{array}{l}\text { Add Human } \\
\text { Capital } \\
\text { Controls } \\
(2)\end{array}$ & $\begin{array}{c}\text { Add } \\
\text { Baseline } \\
\text { Work } \\
(3)\end{array}$ \\
\hline & \multicolumn{3}{|c|}{$\begin{array}{l}\text { A. Proportion of Weeks Worked } \\
\qquad(N=10,243)\end{array}$} \\
\hline \multicolumn{4}{|l|}{ Linear: } \\
\hline Relative age to kindergarten & $\begin{array}{l}.021 * * * \\
(.003)\end{array}$ & $\begin{array}{l}.022 * * * \\
(.003)\end{array}$ & $\begin{array}{l}.026 * * * \\
(.002)\end{array}$ \\
\hline \multicolumn{4}{|l|}{ Quadratic: } \\
\hline Relative age to kindergarten & $\begin{array}{l}.024 * * * \\
(.003)\end{array}$ & $\begin{array}{l}.025 * * * \\
(.003)\end{array}$ & $\begin{array}{l}.029 * * * \\
(.002)\end{array}$ \\
\hline$(\text { Relative age to kindergarten })^{2}$ & $\begin{array}{l}-.0011 * * * \\
(.0004)\end{array}$ & $\begin{array}{l}-.0011 * * * \\
(.0004)\end{array}$ & $\begin{array}{l}-.0012 * * * \\
(.0003)\end{array}$ \\
\hline \multirow[t]{2}{*}{ Average marginal effect } & .022 & .023 & .027 \\
\hline & \multicolumn{3}{|c|}{$\begin{array}{l}\text { B. Hours Worked per Week (in 10s) } \\
\text { in Weeks Worked }(N=7,747)\end{array}$} \\
\hline \multicolumn{4}{|l|}{ Linear: } \\
\hline Relative age to kindergarten & $\begin{array}{l}.030 * * * \\
(.010)\end{array}$ & $\begin{array}{l}.026^{* * *} \\
(.010)\end{array}$ & $\begin{array}{l}.047 * * * \\
(.009)\end{array}$ \\
\hline \multicolumn{4}{|l|}{ Quadratic: } \\
\hline Relative age to kindergarten & $\begin{array}{r}.018^{*} \\
(011)\end{array}$ & .014 & $\begin{array}{l}.036 * * * \\
(010)\end{array}$ \\
\hline${\text { (Relative age to kindergarten })^{2}}^{2}$ & $\begin{array}{l}.0039 * * * \\
(.0015)\end{array}$ & $\begin{array}{l}.0037 * * * \\
(.0014)\end{array}$ & $\begin{array}{l}.0035^{* *} \\
(.0014)\end{array}$ \\
\hline \multirow[t]{2}{*}{ Average marginal effect } & .028 & .024 & .045 \\
\hline & \multicolumn{3}{|c|}{$\begin{array}{l}\text { C. Hours Worked per Week (in 10s) } \\
\text { in All Weeks }(N=10,243)\end{array}$} \\
\hline \multicolumn{4}{|l|}{ Linear: } \\
\hline Relative age to kindergarten & $\begin{array}{l}.093 * * * \\
(.012)\end{array}$ & $\begin{array}{l}.094 * * * \\
(.012)\end{array}$ & $\begin{array}{l}.115^{* * * *} \\
(.010)\end{array}$ \\
\hline \multicolumn{4}{|l|}{ Quadratic: } \\
\hline Relative age to kindergarten & $\begin{array}{l}.096 * * * \\
(.012)\end{array}$ & $\begin{array}{l}.097 * * * \\
(.012)\end{array}$ & $\begin{array}{l}.120 * * * \\
(.010)\end{array}$ \\
\hline${\text { (Relative age to kindergarten })^{2}}^{2}$ & $\begin{aligned}-.0009 \\
(.0015)\end{aligned}$ & $\begin{aligned}-.001 \\
(.002)\end{aligned}$ & $\begin{array}{l}-.0016 \\
(.0015)\end{array}$ \\
\hline Average marginal effect & .094 & .095 & .117 \\
\hline
\end{tabular}

Note.-Standard errors, which are heteroscedasticity robust and clustered by mother, are in parentheses. Year fixed effects are included. Mother's sampling weights are used. In col. 1, we include only demographic controls: mother is Hispanic, mother is non-Hispanic black, family size, mother's age in years, spouse's age in years ( 0 if no spouse), mother is married and lives with spouse, child is female, child's age in months, and attachment to biological father. In col. 2, we add human capital controls-mother's AFQT score (2006 standardization), mother's education (high school graduate, some college, and college degree or higher), and spouse's education (high school graduate, some college, and college degree or higher; all are 0 if no spouse) - in addition to the demographic controls. In col. 3, we further add the baseline value of the work outcome.

* Statistically significant at the 10 percent level.

** Statistically significant at the 5 percent level.

*** Statistically significant at the 1 percent level. 
results for hours worked per week (in 10s) in weeks worked. The coefficient estimates for relative age and its square are always positive, and the squared term is always significant. This implies a positive and increasing marginal effect. ${ }^{12}$ Panel C displays the results for hours worked per week (in 10s) across all weeks, including those not worked. Youngest child's relative age is significant in all regressions, regardless of whether a linear or quadratic functional form is used, with an additional year of age leading to $0.93-1.2$ additional work hours. Interestingly, although the coefficient estimate on the squared term is consistently negative, it is never close to statistically significant, and its magnitude is very small. In other words, a linear functional form appears sufficient when hours per week across all weeks is the outcome.

Table 3 presents the results for the mother's spouse's work outcomes. Consistent with the semiparametric results, there is very little evidence that youngest child's relative age meaningfully influences spouse's labor supply. When relative age is modeled linearly, its coefficient estimates are never statistically significant, and they are very small in magnitude, compared to the corresponding estimates for mothers. While several coefficient estimates are statistically significant when the quadratic specification is used, they tend to offset each other when the average marginal effects are computed. For instance, consider the quadratic regression with the full set of control variables for hours worked per week in all weeks (col. 3, "quadratic" rows). The coefficient estimate for relative age is a weakly significant 0.018 , while that for the squared term is a weakly significant -0.003 . Combining these leads to an average marginal effect across spouses in the sample of just 0.013 , which is almost an order of magnitude less than the corresponding average marginal effect for mothers of $0.117 .{ }^{13}$

In sum, the results from the semiparametric and parametric models yield three key insights. First, youngest child's relative age increases only

\footnotetext{
12 This increase in work hours along the intensive margin could be driven by either longer hours worked at the same job or a switch to a new job where more hours are required but earning potential is greater. In an effort to distinguish between these two possibilities, we examined effects of youngest child's relative age on recent job changes (defined as tenure at current job being less than a year) and wages (earnings per hour for salaried workers). When we control for the demographic and human capital variables, an additional year of age relative to kindergarten is associated with a small ( 0.2 percentage points) and statistically insignificant $(p=.322)$ increase in the probability of having a recent job change among those who were already employed at the last survey wave $(n=6,850)$. Accordingly, each year of relative age is associated with a statistically insignificant $(p=.237)$ wage reduction of 67 cents. Together, these results suggest that the intensive-margin effects are mainly attributable to working longer hours at the same job.

${ }^{13}$ One potential concern with the above analyses is that the sample selection criteriamothers with at least two children where the older ones are between 7 and 17 years oldraise questions about generalizability. To address this issue, we reestimate the parametric models, using a broader sample of all mothers with any children 17 or younger. The results for this "unrestricted sample" from regressions with the demographic and human capital controls and a linear functional form for relative age are shown in table A1 (tables A1 and A2 are available online), alongside the results from the analogous specifications in tables 2 and 3 ("main sample"). In spite of the fact that relaxing the selection criteria roughly doubles the sample size, the results remain very similar.
} 
TABLE 3

Effects of Youngest Child's Relative Age to Kindergarten ON MOTHER's SPOUSE's WORK

\begin{tabular}{|c|c|c|c|}
\hline & $\begin{array}{c}\text { Demographic } \\
\text { Controls } \\
(1)\end{array}$ & $\begin{array}{c}\text { Add Human } \\
\text { Capital Controls } \\
(2)\end{array}$ & $\begin{array}{c}\text { Add Baseline } \\
\text { Work } \\
(3)\end{array}$ \\
\hline & \multicolumn{3}{|c|}{$\begin{array}{l}\text { A. Proportion of Weeks Worked } \\
\qquad(N=6,477)\end{array}$} \\
\hline \multicolumn{4}{|l|}{ Linear: } \\
\hline Relative age to kindergarten & $\begin{array}{l}.0001 \\
(.002)\end{array}$ & $\begin{array}{l}.002 \\
(.002)\end{array}$ & $\begin{array}{l}.001 \\
(.001)\end{array}$ \\
\hline \multicolumn{4}{|l|}{ Quadratic: } \\
\hline Relative age to kindergarten & $\begin{array}{l}.001 \\
(.002)\end{array}$ & $\begin{array}{l}.002 \\
(.002)\end{array}$ & $\begin{array}{l}.001 \\
(.002)\end{array}$ \\
\hline${\text { (Relative age to kindergarten })^{2}}^{2}$ & $\begin{array}{r}-.0003 \\
(.0002)\end{array}$ & $\begin{aligned}-.0002 \\
(.0002)\end{aligned}$ & $\begin{aligned}-.0001 \\
(.0002)\end{aligned}$ \\
\hline \multirow[t]{2}{*}{ Average marginal effect } & .0004 & .002 & .001 \\
\hline & \multicolumn{3}{|c|}{$\begin{array}{l}\text { B. Hours Worked per Week (in 10s) } \\
\text { in Weeks Worked }(N=6,196)\end{array}$} \\
\hline \multicolumn{4}{|l|}{ Linear: } \\
\hline Relative age to kindergarten & $\begin{array}{l}.006 \\
(.008)\end{array}$ & $\begin{array}{l}.009 \\
(.008)\end{array}$ & $\begin{array}{l}.008 \\
(.007)\end{array}$ \\
\hline \multicolumn{4}{|l|}{ Quadratic: } \\
\hline Relative age to kindergarten & $\begin{array}{l}.014 \\
(.009)\end{array}$ & $\begin{array}{l}.017 * \\
(.009)\end{array}$ & $\begin{array}{l}.015^{*} \\
(.008)\end{array}$ \\
\hline$(\text { Relative age to kindergarten })^{2}$ & $\begin{array}{l}-.003^{* *} \\
(.001)\end{array}$ & $\begin{array}{l}-.003^{* *} \\
(.001)\end{array}$ & $\begin{array}{l}-.003^{* *} \\
(.001)\end{array}$ \\
\hline \multirow[t]{2}{*}{ Average marginal effect } & .009 & .012 & .010 \\
\hline & \multicolumn{3}{|c|}{$\begin{array}{l}\text { C. Hours Worked per Week (in 10s) } \\
\text { in All Weeks }(N=6,477)\end{array}$} \\
\hline \multicolumn{4}{|l|}{ Linear: } \\
\hline Relative age to kindergarten & $\begin{array}{l}.007 \\
(.010)\end{array}$ & $\begin{array}{l}.017 \\
(.011)\end{array}$ & $\begin{array}{l}.010 \\
(.009)\end{array}$ \\
\hline \multicolumn{4}{|l|}{ Quadratic: } \\
\hline Relative age to kindergarten & $\begin{array}{l}.019 \\
(.012)\end{array}$ & $\begin{array}{l}.028 * * \\
(.012)\end{array}$ & $\begin{array}{l}.018^{*} \\
(.011)\end{array}$ \\
\hline$(\text { Relative age to kindergarten })^{2}$ & $\begin{array}{l}-.004^{* * * *} \\
(.002)\end{array}$ & $\begin{array}{l}-.004 * * \\
(.002)\end{array}$ & $\begin{array}{c}-.003^{*} \\
(.001)\end{array}$ \\
\hline Average marginal effect & .011 & .020 & .013 \\
\hline
\end{tabular}

Note.-Standard errors, which are heteroscedasticity robust and clustered by mother, are in parentheses. Year fixed effects are included. Mother's sampling weights are used. The sample excludes unmarried mothers. In col. 1, we include only demographic controls: mother is Hispanic, mother is non-Hispanic black, family size, mother's age in years, spouse's age in years ( 0 if no spouse), mother is married and lives with spouse, child is female, child's age in months, and attachment to biological father. In col. 2, we add human capital controlsmother's AFQT score (2006 standardization), mother's education (high school graduate, some college, and college degree or higher), and spouse's education (high school graduate, some college, and college degree or higher; all are 0 if no spouse) - in addition to the demographic controls. In col. 3, we further add the baseline value of the work outcome. * Statistically significant at the 10 percent level.

** Statistically significant at the 5 percent level.

*** Statistically significant at the 1 percent level. 
mothers' labor supply, as opposed to that of both mothers and their spouses. Second, this increase occurs along both the extensive and intensive margins. Third, this increase is gradual rather than sudden.

\section{Subsample Analyses}

Table 4 returns to the original age cutoffs and reports the results for several subsamples. The objective is to examine whether parents' labor supply responses to their youngest child growing up vary with the household's relative level of disadvantage. On one hand, parents in disadvantaged households may be less able than others to leave the labor force to care for children, implying less of a "bounce-back" effect as the children age into public schools. On the other hand, parents in disadvantaged households who do leave the labor force may feel a relatively strong need to earn additional income once they have access to free child care through the school system. Columns 1 and 2 stratify on the basis of whether a parent in the household has any college education. Columns 3 and 4 divide the sample by whether the mother is Hispanic or black. Next, we stratify by the mother's marital status, with the sample restricted in column 5 to unmarried mothers, in column 6 to married mothers for whom the child's biological father lives in the home (indicating that the mother is likely married to the biological father), and in column 7 to other married mothers (those who are likely married to the child's stepfather). Columns 8 and 9 borrow from Ruhm (2008) and split the sample on the basis of a "disadvantage index" that represents the predicted value of a regression of household income on mother's age, AFQT score, and education and the presence of a spouse/partner. The advantage of stratifying by predicted rather than actual income is that it circumvents the endogenous sample selection problem caused by income being a function of work hours.

The results in table 4 show that the relationship between youngest child's relative age and parents' work is remarkably similar across the various subsamples. ${ }^{14}$ In all cases, relative age is a statistically significant predictor (at the 1 percent level) of mother's work, and the magnitudes are all within a tight range of $0.95-1.21$ hours per week. Again in all cases, the associations are much smaller for spouse's work, ranging from -0.08 to 0.37 hours per week. We do observe statistically significant, though small, increases in spouse's work hours for two of the seven subsamples: those where the parents have no college education and those where the mother is Hispanic/black.

\footnotetext{
14 To save space, for these subsamples we report only the results using a linear functional form for relative age and hours worked per week across all weeks as the measure of work. The results using quadratic and semiparametric models and the other work outcomes are qualitatively similar and available upon request.
} 


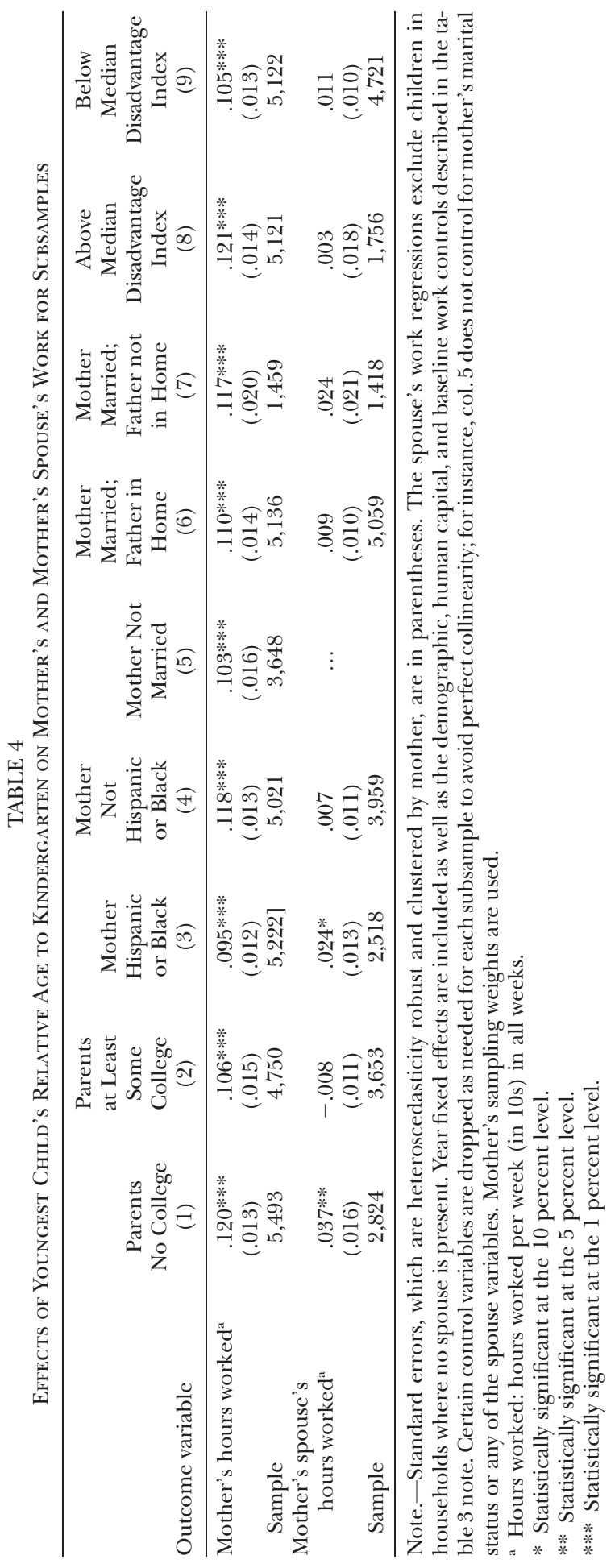

This content downloaded from 131.204.174.047 on August 10, 2020 13:36:41 PM All use subject to University of Chicago Press Terms and Conditions (http://www.journals.uchicago.edu/t-and-c). 


\section{Effect of Parents' Work on Childhood Obesity}

\section{A. Models}

The key results from Section III have implications for the appropriate design of an IV model that uses youngest child's relative age as an instrument to estimate the effect of parental work on childhood obesity. First, since the instrument has little to no predictive power for spouses' work, the IV model should focus only on the impact of mothers' work. We explore below whether the IV estimate for mother's work changes if we control for spouse's work, but our estimate for spouses' work should not itself be considered causal. Second, the appropriate endogenous variable is mother's work hours per week over all weeks, since it incorporates both the intensive and extensive margins. Merely using a dummy for maternal employment, as in Morrill (2011), could lead to a violation of the exclusion restriction, since intensity of work would be in the second-stage error term. Third, since this particular endogenous variable is essentially linearly associated with relative age, a linear functional form for the instrument is sufficient. Using a dummy for kindergarten eligibility, again as in Morrill (2011), would result in a weaker-than-necessary instrument.

Accordingly, the IV model takes the form

$$
\begin{gathered}
\operatorname{MWORK}_{i t}=\alpha_{0}+\alpha_{1} \operatorname{RELAGE}_{i t}+\boldsymbol{\alpha}_{2} \boldsymbol{X}_{i t}+\boldsymbol{\alpha}_{3} \boldsymbol{Y}_{c i t}+\tau_{2 t}+\varepsilon_{2 c i t}, \\
\mathrm{BMI}_{c i t}=\theta_{0}+\theta_{1} \widehat{\operatorname{MWORK}}_{i t}+\boldsymbol{\theta}_{2} \boldsymbol{X}_{i t}+\boldsymbol{\theta}_{3} \boldsymbol{Y}_{c i t}+\tau_{3 t}+\varepsilon_{3 c i t},
\end{gathered}
$$

where equation (2) is the first-stage regression for mother's work hours per week over all weeks $\left(\mathrm{MWORK}_{i t}\right)$ and equation (3) is the second stage for children's weight status $\left(\mathrm{BMI}_{c i t}\right)$. The $c$ subscript indexes children; variables without a $c$ subscript are defined at the mother's level and are therefore the same for all children of mother $i$ in the sample. Here, $\mathrm{BMI}_{c i t}$ is one of the child-BMI-related outcome variables: BMI $z$-score, overweight, and obese; RELAGE ${ }_{i t}$ is again youngest child's age (in years, with fractions allowed) relative to the kindergarten eligibility cutoff; $\boldsymbol{X}_{i t}$ and $\boldsymbol{Y}_{c i t}$ are the mother- and child-level control variables, respectively; $\tau_{2 t}$ and $\tau_{3 t}$ are the year fixed effects in equations (2) and (3), respectively; and $\varepsilon_{2 c i t}$ and $\varepsilon_{3 c i t}$ are the respective error terms.

The coefficient of interest $\theta_{1}$ provides the local average treatment effects (LATEs) of mothers' work hours on children's weight outcomes - that is, the effects of changes in work hours on older children's weight induced by the youngest sibling's age relative to the kindergarten entry threshold. The fact that the first-stage estimates are similar across various subsamples, as discussed in Section III, provides some confidence that the LATEs are representative of population-wide effects. Given the nature of the data and the identification strategy, these effects should be interpreted as capturing relatively short-run effects, compared to the results of some papers that measure maternal work as averages over the course of the child's entire 
life (e.g., Anderson et al. 2003; Ruhm 2008; Courtemanche 2009). While the capital-stock nature of body weight suggests that the long-run effects should exceed the short-run effects, evidence from multiple disciplines suggests that sizeable short-run effects are plausible. Childhood BMI is highly variable, with a number of studies reporting average annual BMI changes of around one unit (Berkey et al. 2003; Sawyer et al. 2011). Additionally, Millimet and Tchernis (2015) show that there is substantial mobility across the BMI distribution among children in the United States. For example, children who are in the bottom quartile of the BMI distribution during fall of kindergarten have a 40 percent chance of moving at least 10 percentile points by spring of first grade, with males and minorities showing slightly higher levels of mobility. ${ }^{15}$ Finally, numerous studies find that changes in economic variables can contemporaneously lead to meaningful changes in both adult and child weight. ${ }^{16}$

The validity of the IV model depends on two key assumptions. First, youngest child's age relative to kindergarten eligibility must have a sufficiently strong effect on mother's work hours. We evaluate this assumption through $F$-tests of the significance of the instrument in the first-stage regressions. Second, youngest child's relative age must be excludable from the second-stage regression, meaning that, conditional on the controls, it is related only to the focal child's weight via its effect on maternal work. This assumption is more difficult to test directly. Following our discussion of the main results, we attempt to rule out several possible threats to the exclusion restriction.

\section{B. Results}

Table 5 reports the results of interest from the IV regressions. The three panels display the results for the three weight outcomes. The top row of each panel contains OLS results for the sake of comparison. The second row presents the second-stage coefficient estimates of interest from the IV models. The remaining rows show results from the first-stage $F$-test and the test for endogeneity of mother's work. As with the analyses in Section III, we gradually build up the set of control variables, starting with only the demographic controls (for both mother and child) in column 1, adding the human capital controls in column 2, and then adding the baseline value of the outcome variable in column 3 . We also consider three additional specifications in this section: adding the child health controls

\footnotetext{
15 BMIs are professionally measured in the data used by Sawyer et al. (2011) and Millimet and Tchernis (2015), so these sizeable fluctuations cannot merely be attributed to the wellknown phenomenon of measurement error in self-reported height and weight.

16 For a recent review of the literature on the economic causes of child and adult obesity, see Cawley (2015). For a discussion of the literature on the economic causes of adult obesity, as well as estimates of the short-run effects of 27 different economic variables, see Courtemanche et al. (2016). Cutler, Glaeser, and Shapiro (2003) argue that, based on food and time diary evidence, changes in weight over time appear attributable mostly to dietary habits, as opposed to physical activity.
} 
in column 4, further adding spouse's hours worked per week across all weeks ( 0 if no spouse or spouse does not work) in column 5, and finally, using a quadratic rather than a linear functional form for RELAGE in $_{i t}$ in column 6.

We begin by discussing the OLS results. Ten additional maternal work hours per week are associated with statistically significant but small increases in BMI $z$-score of $0.029-0.04$ and $\operatorname{Pr}$ (overweight) of $0.7-0.8$ percentage points. The estimates for $\operatorname{Pr}$ (obese) are also positive and small-0.4-0.5 percentage points - but are statistically insignificant in five of the six specifications.

The IV estimates are, in all cases, positive and substantially larger than the corresponding OLS estimates. Ten additional maternal work hours per week are predicted to increase BMI $z$-score by $0.15-0.23$ units, $\operatorname{Pr}$ (overweight) by 7.1-8.4 percentage points, and $\operatorname{Pr}$ (obese) by $5.3-6.3$ percentage points. The impacts on overweight and obesity are statistically significant at the 10 percent level or better in all specifications, while the effect on BMI $z$-score is consistently significant at the 5 percent level after the baseline weight outcome is added (cols. 3-6). While the IV point estimates and levels of statistical significance are somewhat sensitive to the inclusion of control variables, the changes are never statistically significant; in fact, the estimates never vary by more than 1 standard error. The first-stage $F$-statistics are all over 26 - well above the conventional rule of thumb of 10 - when relative age is the only instrument (cols. 1-5). They drop to around 17 when both relative age and its square are used as instruments (col. 6). The endogeneity test rejects (at the 10 percent level or better) the null hypothesis that the OLS estimator is consistent in all overweight and obesity regressions as well as in all BMI $z$-score regressions that include baseline weight. ${ }^{17}$

Further discussion is warranted regarding magnitudes. The IV point estimates represent 13-22 percent, 15-18 percent, and 15-18.7 percent of the sample standard deviations for BMI $z$-score, overweight, and obesity, respectively, and 27-32 percent and 45-54 percent of the sample rates of overweight and obesity, respectively. ${ }^{18}$ While these effects sound very large, the underlying weight gain behind them seems plausible. In our sample,

\footnotetext{
${ }^{17}$ We also explored whether mother's work hours influence the probability that a child is underweight, defined as having a BMI for age below the 10th percentile on the CDC growth charts (http://www.kdheks.gov/nws-wic/download/13-UnderweightChildren .pdf; accessed 8/3/18). Including the full set of controls, the OLS estimate suggests that each 10 hours of mother's work reduces the probability a child is underweight by 0.7 percentage points $(p=.001)$, relative to a sample rate of around 8 percent. However, with IVs, this estimate becomes nearly zero $(0.1$ percentage points; $p=.952)$. The OLS estimate therefore appears attributable to reverse causality (mothers leaving the labor force to care for a sick child) or omitted-variable bias (less conscientious mothers both having malnourished children and relatively low labor supply).

18 These calculations are based on dividing the coefficient estimates by the standard deviations and sample means reported in table 1 and then multiplying by 100 percent. Note that the coefficient estimate for BMI z-score is not exactly interpretable as the effect in standard deviations, because $z$-score is based on the historical CDC growth charts rather than an in-sample calculation.
} 


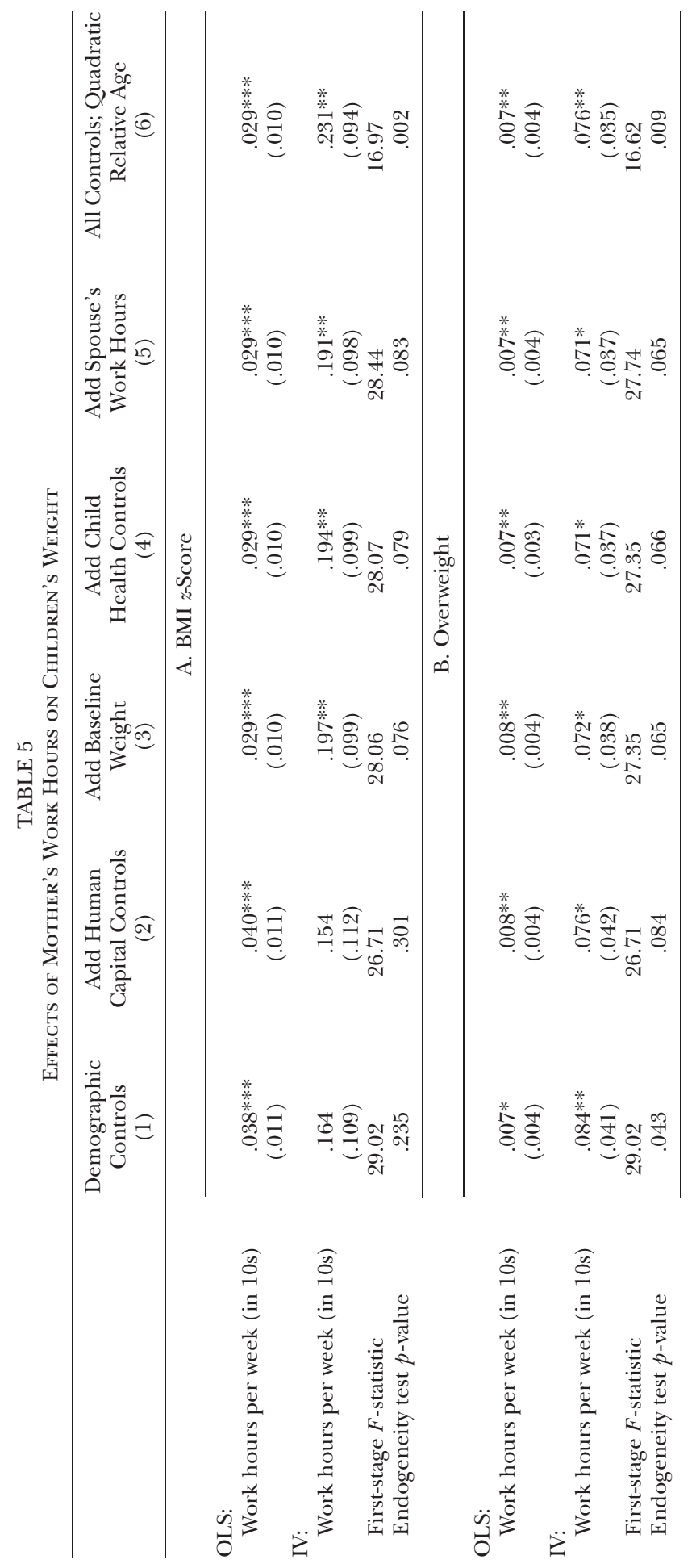

572

This content downloaded from 131.204.174.047 on August 10, 2020 13:36:41 PM 


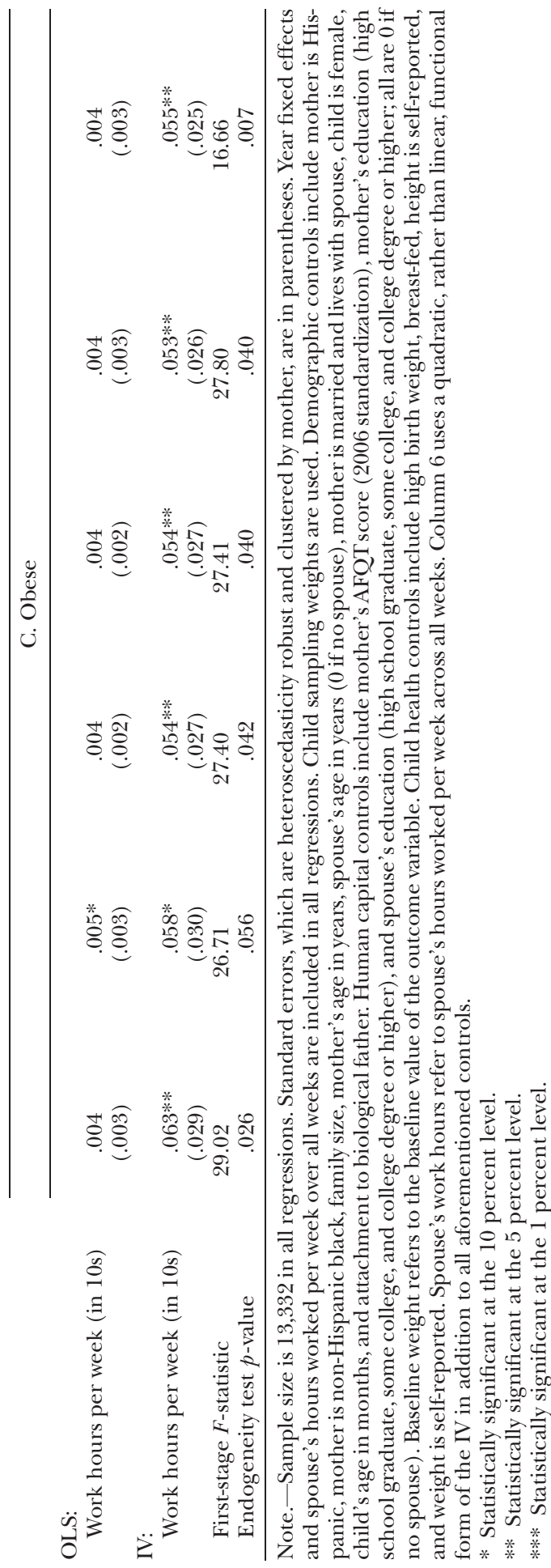


the standard deviation for BMI is 4.7 units, meaning that 13-22 percent of a standard deviation is $0.6-1$ units. At the sample mean height of 60.3 inches, this equates to $3.1-5.2$ pounds. In other words, the $45-54$ percent increase in childhood obesity could be coming from just a 3-5-pound average weight gain. Small average weight gains leading to large percentage changes in obesity are not uncommon in the obesity literature. For instance, a widely cited paper by Cutler et al. (2003) shows that the US adult obesity rate rose by 88 percent between $1971-75$ and 1988-94, but the corresponding increase in average BMI was just 1.9 units, or 12 pounds, at the average adult height. Moreover, our magnitudes are actually more modest than those obtained by Morrill (2011), whose results imply that 10 additional mothers' work hours increase the probability of child hospitalization, injury, and asthma episodes by around 60 percent. ${ }^{19}$

With all that said, we caution against a literal interpretation of our IV point estimates, because they are accompanied by fairly wide confidence intervals - as evidenced by the fact that the estimates never reach the 1 percent level of statistical significance, despite their size. This is likely due to the relatively modest sample size of the NLSY79, combined with the fact that the instrument, though strong enough to rule out substantial weakinstrument bias, is not overwhelmingly strong. Nonetheless, it is noteworthy that, in spite of the relative imprecision of the IV estimates, we are still able to reject the consistency of the OLS estimator in most cases. All things considered, our preferred interpretation of the results is simply that they provide evidence that maternal work increases child weight and that the magnitude of the effect is understated if the endogeneity of work is ignored.

\section{Alternative Explanations}

In this section, we discuss alternative possible explanations for our findings and provide checks of the extent to which they are problematic. With regard to internal validity, the key assumption in the IV model is that youngest sibling's age is related to older sibling's BMI only via mother's work hours. One potential concern is that the youngest child becoming eligible for kindergarten might relax a mother's time constraint more generally, freeing up time not only for market work but also for activities, such as exercise and food preparation, that could conceivably affect the weights of her children. For instance, if a mother begins an exercise program and develops enthusiasm for it, she may seek to also increase the physical activity of her children. If she has more time to prepare home-cooked meals, this would presumably decrease reliance on restaurant food and lead to healthier eating habits for the entire family. While we cannot rule out such scenarios, it is important to note that they both point in the direction of youngest child's relative age reducing, rather than increasing, children's

19 Morrill (2011) actually reports that a dummy variable for maternal employment increases these episodes by around 200 percent. To facilitate a comparison to our estimated effects of 10 work hours, we divide by 3.5, yielding approximately 60 percent, since the average working mother in our sample works around 35 hours per week. 
BMI. They would therefore cause us to underestimate the impact of parental work on children's BMI, meaning that the large effects documented in the preceding section would actually be conservative.

Another possible issue is that as the youngest child gets older, older children in the household become more mature and independent while parents become more experienced, both of which could influence the focal child's weight. However, in this scenario, the confounders are actually age of the focal child and age of the parents - variables that are included in our set of demographic controls - rather than the youngest child's age per se. In other words, we do not see a compelling reason that youngest child's age should be associated with an older child's maturity and parents' ability after conditioning on the older child's and parents' own ages. Moreover, the direction of the bias should again work against our results, as presumably maturity and experience lead to healthier decisions.

Another potential concern is that the youngest child aging into kindergarten likely increases disposable income for at least some mothers by reducing the need for paid child care. This additional income could conceivably be spent on either health-promoting (e.g., fresh produce) or health-detracting (e.g., junk food) items. However, we do not believe that this income effect is likely to be consequential for our results. Household income is well known to be negatively associated with childhood obesity (e.g., Singh et al. 2008), implying that the income effect would work in the direction of making our IV estimates more conservative. That said, whether this relationship is causal remains an open question, and it is also possible that earned income might affect health differently than a reduction in expenditures, which is essentially unearned income.

To address both of these issues, we use our data to investigate the effect of income on child weight. We (at least partially) address the concern of causality by including child fixed effects, and we address the issue of earned versus unearned income by including not only household income but also benefits received from welfare/Temporary Assistance for Needy Families (TANF). Results from regressions with the full set of controls for each of the three outcomes are shown in table 6. In OLS regressions that do not include child fixed effects, we observe the expected negative relationship between household income and the child weight outcomes but no significant effects of welfare/TANF benefits. In the fixed-effects regressions, we observe no significant effects of either household income or welfare/TANF on any of the child weight outcomes, and the magnitudes of the coefficient estimates are small (e.g., an additional $\$ 1,000$ of income reduces the probability of being obese by less than one-one-hundredth of a percentage point). In sum, the available evidence suggests that it is unlikely that the income effect is sufficiently large for the potential decline in child care expenses after the youngest child becomes eligible for kindergarten to meaningfully influence child weight.

An additional possible concern is that parental attitudes toward health may change systematically with the youngest child's age. For instance, if parents relax their emphasis on healthy behaviors as their children start 
TABLE 6

EFFect of Different Income SOURCes on ChILDREN's Weight

\begin{tabular}{|c|c|c|}
\hline Income/Benefits (in $\$ 000$ s) & $\begin{array}{l}\text { OLS } \\
(1)\end{array}$ & $\begin{array}{l}\text { Child Fixed Effects } \\
\text { (2) }\end{array}$ \\
\hline & \multicolumn{2}{|c|}{ A. BMI z-Score } \\
\hline Household income & $\begin{array}{c}-.0004 * \\
(.0002)\end{array}$ & $\begin{array}{c}-.0002 \\
(.0002)\end{array}$ \\
\hline \multirow[t]{2}{*}{ Welfare/TANF benefits } & $\begin{array}{c}-.004 \\
(.003)\end{array}$ & $\begin{array}{c}-.0006 \\
(.002)\end{array}$ \\
\hline & \multicolumn{2}{|c|}{ B. Overweight } \\
\hline Household income & $\begin{array}{c}-.0001 * \\
(.0001)\end{array}$ & $\begin{array}{c}-.0001 \\
(.0001)\end{array}$ \\
\hline \multirow[t]{2}{*}{ Welfare/TANF benefits } & $\begin{array}{c}-.0008 \\
(.001) \\
\end{array}$ & $\begin{array}{r}-.0006 \\
(.001)\end{array}$ \\
\hline & \multicolumn{2}{|c|}{ C. Obese } \\
\hline Household income & $\begin{array}{c}-.0001 * * * \\
(.00004)\end{array}$ & $\begin{array}{r}-.00003 \\
(.00004)\end{array}$ \\
\hline Welfare/TANF benefits & $\begin{array}{l}-.0003 \\
(.0007)\end{array}$ & $\begin{array}{l}.0005 \\
(.0007)\end{array}$ \\
\hline
\end{tabular}

Note.-Sample size is 13,175 in all regressions. Standard errors, which are heteroscedasticity robust and clustered by mother, are in parentheses. Year fixed effects and the demographic, human capital, and child health controls are included. Demographic controls include mother is Hispanic, mother is non-Hispanic black, family size, mother's age in years, spouse's age in years (0 if no spouse), mother is married and lives with spouse, child is female, child's age in months, and attachment to biological father. Human capital controls include mother's AFQT score (2006 standardization), mother's education (high school graduate, some college, and college degree or higher), and spouse's education (high school graduate, some college, and college degree or higher; all are 0 if no spouse). Child health controls include high birth weight, breast-fed, height is self-reported, and weight is self-reported. Child sampling weights are used.

* Statistically significant at the 10 percent level.

*** Statistically significant at the 1 percent level.

to require less direct supervision, we might observe an increase in child BMI even if the parents' work schedules do not change. This would lead to upward bias in the IV estimator. In table 7, we present results from falsification tests designed to rule out the possibility of confounding from such changes in attitudes toward health. Specifically, we reestimate our IV model by using each of four different outcomes that reflect health attitudes but should not be causally affected by work: whether the mother is currently trying to lose weight, whether the mother always or often reads nutritional information (as opposed to sometimes, rarely, or never), whether the child had a well-patient doctor checkup in the past year, and whether the child had a dental checkup in the past 6 months. ${ }^{20}$ The first

${ }^{20}$ One might worry that these outcomes do not provide "pure" falsification tests, because stories could be devised in which they could plausibly be affected by parental work. We conducted additional analyses (results available upon request) to rule out at least the most obvious of these stories. Specifically, a mother might gain weight herself after returning to 
TABLE 7

Falsification Tests of Mother's Hours Worked Per Week (in 10s) over All Weeks on Various Health Attitudes Outcomes

\begin{tabular}{|c|c|c|c|c|}
\hline & $\begin{array}{l}\text { Mother Trying } \\
\text { to Lose Weight } \\
\text { (1) }\end{array}$ & $\begin{array}{l}\text { Mother Always } \\
\text { or Often Reads } \\
\text { Nutritional } \\
\text { Information } \\
\text { (2) }\end{array}$ & $\begin{array}{c}\text { Child Had } \\
\text { Doctor Checkup } \\
\text { in Past Year } \\
\text { (3) }\end{array}$ & $\begin{array}{c}\text { Child Had } \\
\text { Dental Checkup } \\
\text { in Past } 6 \text { Months } \\
\text { (4) }\end{array}$ \\
\hline Sample & 2,292 & 2,287 & 9,493 & 9,492 \\
\hline IV model & $\begin{array}{l}.044 \\
(.061)\end{array}$ & $\begin{array}{l}.006 \\
(.053)\end{array}$ & $\begin{array}{c}-.007 \\
(.040)\end{array}$ & $\begin{array}{c}.069 \\
(.043)\end{array}$ \\
\hline First-stage $F$-statistic & 15.07 & 16.67 & 28.27 & 27.52 \\
\hline
\end{tabular}

Note.-Standard errors, which are heteroscedasticity robust and clustered by mother, are in parentheses. Year fixed effects and the demographic and human capital controls are included. Child health controls are also included in the child-level regressions in cols. 3 and 4. Mother's sampling weights are used for cols. 1 and 2, whereas children's sampling weights are used for cols. 3 and 4. Demographic controls include mother is Hispanic, mother is non-Hispanic black, family size, mother's age in years, spouse's age in years ( 0 if no spouse), mother is married and lives with spouse, child is female, child's age in months, and attachment to biological father. Human capital controls include mother's AFQT score (2006 standardization), mother's education (high school graduate, some college, and college degree or higher), and spouse's education (high school graduate, some college, and college degree or higher; all are 0 if no spouse). Child health controls include high birth weight, breast-fed, height is self-reported, and weight is self-reported.

two regressions involve mothers' outcomes, so we utilize the mother-level data set used in Section III. We use the child-level data set for the last two regressions, as those feature children's outcomes. If the IV models reveal "effects" on these outcomes, this would suggest a violation of the exclusion restriction that the youngest child's age instruments affect healthrelated outcomes only via parental work. Reassuringly, we find no evidence of any such effects, as the coefficient of interest is insignificant in all cases. ${ }^{21}$

\section{Subsample Analyses}

We next reestimate the IV models for the education, race/ethnicity, mother's marital status, and disadvantage index subsamples introduced in Section III. Given the complexity of the mechanisms involved, it is unclear

work, which could potentially increase her likelihood of making weight loss attempts or showing an interest in nutritional information. We therefore verified that our results for these outcomes are robust to the inclusion of mother's BMI (or overweight or obesity status) as a control. For the child health care outcomes, perhaps additional parental work could influence these by increasing income. We therefore verified that the results are robust to the inclusion of income and/or health insurance status (which likely affects the income elasticity of health care).

21 As in Sec. III, external validity is another potential concern, as results from a sample of 717-year-old children with at least one younger sibling might not generalize to other children. To at least partially address this issue, we reestimate the OLS models with a broader sample of all children between the ages of 3 and 17 (the same age cutoffs used by Courtemanche 2009). The results, shown in table A2, are virtually identical to those from the main analysis sample. 
whether the effects should be larger for advantaged or disadvantaged households. The effect might be smaller for advantaged households if, for instance, they are better able than disadvantaged households to arrange for alternate supervision once the mother returns to work. On the other hand, if home-cooked meals in disadvantaged households tend to be more caloric than those in advantaged households, then an increased reliance on pre-prepared meals or fast food might be more consequential for the latter.

Anderson et al. (2003) find that the association between mothers' work and childhood obesity is strongest for children in households with a high income, with a highly educated mother, and with non-Hispanic white race/ethnicity. Accordingly, Ruhm (2008) finds that this relationship is strongest for white children, those with a highly educated mother, those where a spouse/partner is present, and those below the median on the disadvantage index. Fertig et al. (2009) document similar heterogeneity by education. Our objective is to test whether this finding that the association between work hours and child weight is concentrated among advantaged households persists in IV analyses that account for endogeneity.

Table 8 presents the results for the subsamples. Columns 1 and 2 stratify by education. The IV estimates are positive in all cases for both subsamples, but the effects of mother's work on BMI z-score and overweight are notably larger for the higher-education group. Columns 3 and 4 divide the sample by race/ethnicity. The effects are almost completely concentrated among the non-Hispanic, nonblack subsample, as the magnitudes are large and statistically significant for all three weight outcomes for that group, as opposed to small and insignificant for the Hispanic/black group. Stratifying by mother's marital status in columns 5 and 6 , we see that the impacts are large and significant for children whose mothers are married and small and insignificant for those whose mothers are single. In columns 7 and 8, we see that the effects on all three outcomes are clearly concentrated among the more advantaged group (below median disadvantage index).

Our finding that the effects are concentrated among the more advantaged subsample, while interesting in and of itself, also helps to rule out another possible concern related to internal validity. When the youngest child begins public school, (s) he becomes eligible for free school breakfast and lunch if the family's income is below 130 percent of the Federal Poverty Line (FPL) and reduced-price meals if income is below 185 percent. $^{22}$ This could mean a larger share of the family's food budget going toward the older children in the household, increasing their weight. However, if such a scenario was a major driver of our results, we would expect

\footnotetext{
${ }^{22}$ See, for instance, https://www.fns.usda.gov/sbp/fact-sheet and https://fns-prod .azureedge.net/sites/default/files/cn/NSLPFactSheet.pdf (accessed 8/7/18).
} 


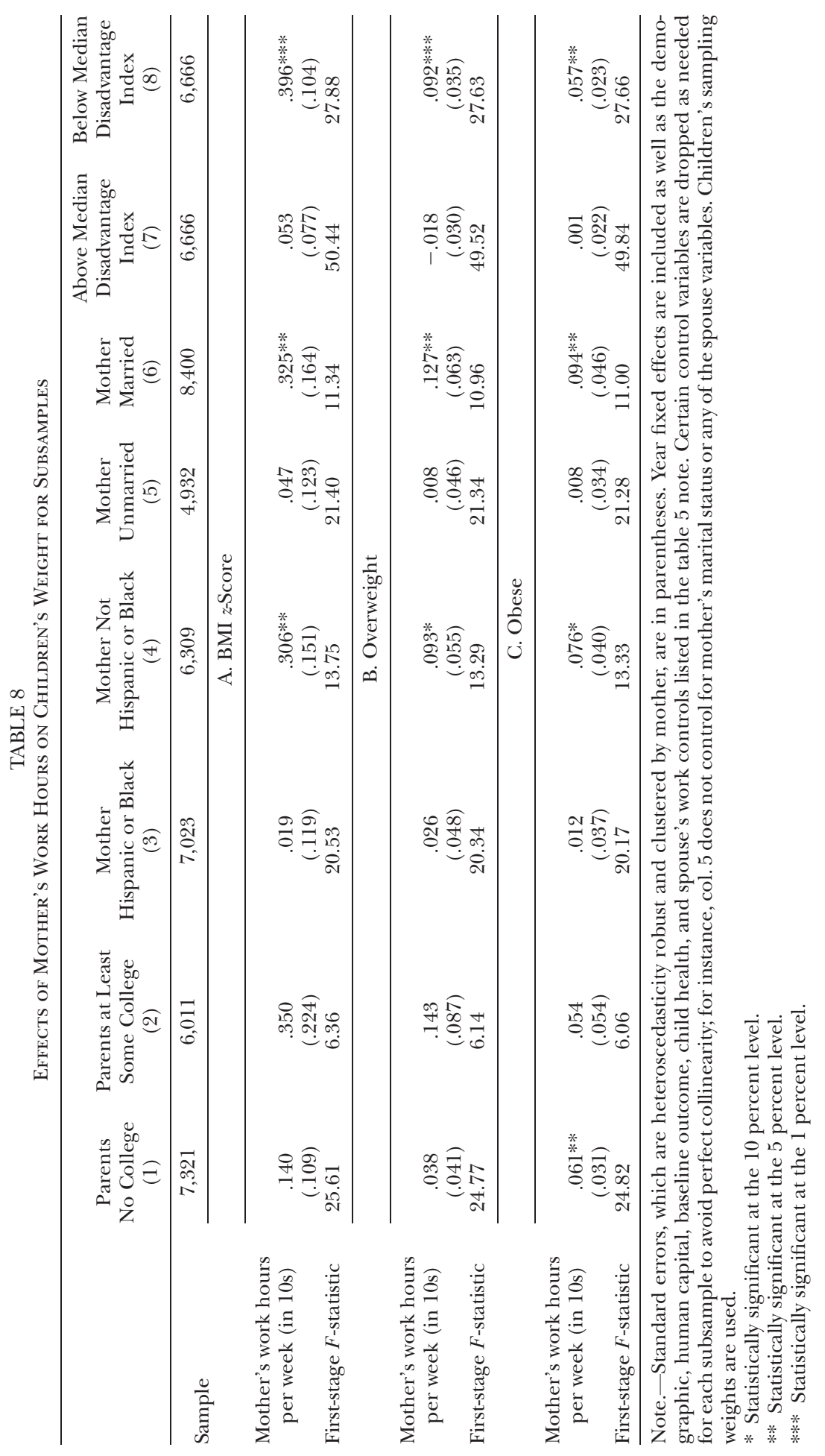

This content downloaded from 131.204.174.047 on August 10, 2020 13:36:41 PM

All use subject to University of Chicago Press Terms and Conditions (http://www.journals.uchicago.edu/t-and-c). 
to see the effects concentrated among the more disadvantaged portion of the sample, and we actually observe just the opposite. ${ }^{23}$

\section{Discussion and Conclusion}

This paper explores the causal effect of maternal employment on child weight. The identification strategy exploits plausibly exogenous variation in mother's labor supply coming from the youngest sibling's age. Using panel data from the NLSY79, we first show that mothers'- but not mothers' spouses' - work hours are responsive to the age of the youngest child. Mothers' work hours gradually increase as the age of the youngest child rises, with the effect occurring along both the extensive and intensive margins of work. We leverage these insights in the design of our IV model, which shows that the impacts of maternal work on children's weight outcomes are positive and large - in most cases, significantly larger than the estimates obtained with OLS.

This finding suggests that the contribution of increased maternal employment to the childhood obesity epidemic is larger than the relatively modest estimates from the prior associational literature would suggest. For instance, Courtemanche (2009) conducts a back-of-the-envelope calculation showing that his estimates imply that the increase in mothers' work hours explain 10 percent of the trend in childhood obesity. Since our IV estimates are roughly three times as large as his estimates, the implication is that the contribution could be closer to 30 percent. Given the relative imprecision of our IV estimates and the dangers of out-of-sample extrapolation, we caution against taking this percentage too literallybut the point is that the contribution to the trend appears to be meaningfully large.

With that said, the results should not be interpreted as discouraging mothers' labor supply or as claiming that the rise in female labor force participation has had a negative net impact on society. The results instead highlight the importance of further investigation into the mechanisms through which maternal employment might affect children's health. Possible mechanisms include the changes in family routine, diet, and time

\footnotetext{
23 We also considered a more direct test of this hypothesis by stratifying on the basis of whether or not the household's children are eligible for free breakfast and lunch, based on income and family size, using the FPL guidelines available at https://familiesusa.org /product/federal-poverty-guidelines (accessed 8/7/18). The results of such a test should be interpreted subject to the caveat that eligibility depends on income and is therefore endogenous to parents' work hours. Nonetheless, we continue to find that the effects are concentrated among the more advantaged group. Among those children eligible for free school meals $(n=6,358), 10$ additional mothers' work hours increase child's BMI $z$-score by $0.086(p=.416), \operatorname{Pr}$ (overweight) by 1 percentage point $(p=.797)$, and $\operatorname{Pr}$ (obese) by 2.3 percentage points $(p=.414)$. Among those eligible only for reduced-price meals or not eligible at all $(n=7,117)$, the effects are much larger: 0.433 for BMI $z$-score $(p=.103), 18.4$ percentage points for $\operatorname{Pr}$ (overweight) $(p=.094)$, and 11.5 percentage points for $\operatorname{Pr}$ (obese) $(p=.121)$.
} 
allocation induced by mothers' labor supply. Maternal employment may reduce beneficial routines, such as regular family meals and physical activities with children, while leading to unhealthy routines, such as television watching and restaurant meals. Prior research has found associations between maternal employment and time use (Fertig et al. 2009; Cawley and Liu 2012), but little causal evidence on mechanisms exists. One exception is a new working paper by Coyer (2016), who uses an identification strategy similar to ours and finds that maternal employment increases purchases of preprepared meals while decreasing fruit, vegetable, and milk purchases.

Another possible mechanism is the child care setting. For example, if child care subsidies, such as the Child Care and Development Fund, encourage working mothers to rely on center-based child care service, the use of nonparental child care may influence children's diet and activity to some extent (Blau and Tekin 2007; Herbst and Tekin 2010). In addition, the availability of relative care, especially from grandparents, has substantial positive effect on mothers' labor supply (Compton and Pollak 2014). Grandparents may put fewer restrictions on their grandchildren's diet and activities (Maher et al. 2008), thus increasing the risk of children being obese.

Not only is understanding the mechanisms of the effects of parental employment on childhood obesity of academic interest, but it would also shed light on policies to help reverse the obesity epidemic. For example, if supervision is an important mechanism, promoting after-school programs could be a beneficial policy. Such programs not only increase children's physical activity level directly but also help children to form healthy habits and promote health education among parents (Annesi et al. 2007; Annesi, Moore, and Dixon 2008). Alternatively, if nutrition is the main mechanism, policies related to food labeling (Bollinger, Leslie, and Sorensen 2010; Tandon et al. 2010) and quality of school meals (Foster et al. 2008; Story, Nanney, and Schwartz 2009) could potentially have an effect. Understanding the relative impact of each of the mechanisms would be the first step toward informing appropriate policy.

Future research should also continue to explore how maternal employment influences children along other dimensions, such as academic performance. For instance, Ruhm (2008), in addition to studying the association between mothers' work hours and adolescents' weight, also examines the verbal, math, and reading performance measures available in the NLSY. The children of working mothers have higher test scores than others, on average. However, this association disappears for the full sample after observable characteristics of the mother, child, and household are controlled for and turns negative when the sample is restricted to children in advantaged households. We investigated these same academic performance outcomes with our IV strategy and found inconclusive results, with the estimates being too imprecise to rule out either zero or meaningfully large effects. ${ }^{24}$ Further

\footnotetext{
${ }^{24}$ For instance, in the IV specification with the full sample and the full set of controls, 10 additional mothers' hours worked per week decrease the Peabody Individual Achievement
} 
study - with either a larger data set or a different identification strategyis therefore necessary to understand the causal effects of maternal employment on these and other outcomes.

\section{References}

Anderson, Patricia M., Kristin F. Butcher, and Phillip B. Levine. 2003. "Maternal Employment and Overweight Children." L. Health Econ. 22:477-504.

Annesi, James J., Avery D. Faigenbaum, Wayne L. Westcott, Alice E. Smith, and Gayle M. Dixon. 2007. "Effects of the Youth Fit for Life Protocol on Physiological Factors, Mood, Self-Appraisal, Voluntary Physical Activity, and Fruit and Vegetable Consumption in Children Enrolled in YMCA After-School Care." J. Soc. Behavioral and Health Sci. 1:86-102.

Annesi, James J., Julie C. Moore, and Gayle M. Dixon. 2008. "Correlates of Changes in Voluntary Physical Activity Associated with the Youth Fit for Life Intervention during After-School Care." Psvcholooical Reports 102:911-19.

Berkey, C. S., H. R. H. Rockett, M. W. Gillman, A. E. Field, and G. A. Colditz. 2003. "Longitudinal Study of Skipping Breakfast and Weight Change in Adolescents." Internat. I. Obesitv 27:1258-66.

Blau, David, and Erdal Tekin. 2007. "The Determinants and Consequences of Child Care Subsidies for Single Mothers in the USA." L. Population Econ. 20:719-41.

Bollinger, Bryan, Phillip Leslie, and Alan Sorensen. 2010. "Calorie Posting in Chain Restaurants.” Working Paper no. 15648 (January), NBER, Cambridge, MA. http:/ / www.nber.org/papers/w15648.

Cascio, Elizabeth U. 2009. "Maternal Labor Supply and the Introduction of Kindergartens into American Public Schools." L. Human Resources 44:140-70.

Cawley, John. 2004. "The Impact of Obesity on Wages." L. Human Resources 39:451-74.

- 2015. "An Economy of Scales: A Selective Review of Obesity's Economic Causes, Consequences, and Solutions." L. Health Econ. 43:244-68.

Cawley, John, and Feng Liu. 2012. "Maternal Employment and Childhood Obesity: A Search for Mechanisms." Econ. and Human Biology 10:352-64.

Cawley, John, and Chad Meyerhoefer. 2012. "The Medical Care Costs of Obesity: An Instrumental Variables Approach.” L. Health Econ. 31:219-30.

Compton, Janice, and Robert A. Pollak. 2014. "Family Proximity, Childcare, and Women's Labor Force Attachment.” L. Urban Econ. 79:72-90.

Courtemanche, Charles. 2009. "Longer Hours and Larger Waistlines? The Relationship between Work Hours and Obesity." Forum Health Econ. and Policy 12 (2): 2. https://doi.org/10.2202/1558-9544.1123.

Courtemanche, Charles, Joshua C. Pinkston, Christopher J. Ruhm, and George L. Wehby. 2016. "Can Changing Economic Factors Explain the Rise in Obesity?" Southern Econ. I. 82 (4): 1266-1310.

Courtemanche, Charles, Joshua C. Pinkston, and Jay Stewart. 2015. "Adjusting Body Mass for Measurement Error with Invalid Validation Data.” Econ. and Human Biology 19:275-93.

Coyer, Christine. 2016. "Into the Workforce and Out of the Home? A Study of Maternal Employment and Food Purchased for At-Home Consumption." Paper

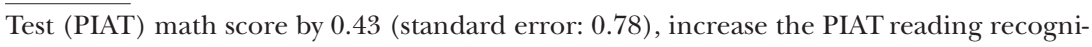
tion score by 0.18 (standard error: 1.25), and increase the Peabody Picture Vocabulary Test by 2.15 (standard error: 1.31). These scores are normalized to have a mean of 100 and a standard deviation of 15 . 
presented at the 6th Biennial Conference of the American Society of Health Economists, Philadelphia, June 12-15. https://ashecon.confex.com/ashecon /2016/webprogram/Paper4397.html.

Cutler, David M., Edward L. Glaeser, and Jesse M. Shapiro. 2003. "Why Have Americans Become More Obese?” J. Econ. Perspectives 17 (3): 93-118.

Evans, William N., Melinda S. Morrill, and Stephen T. Parente. 2010. "Measuring Inappropriate Medical Diagnosis and Treatment in Survey Data: The Case of ADHD among School-Age Children." J. Health Econ. 29:657-73.

Fertig, Angela, Gerhard Glomm, and Rusty Tchernis. 2009. "The Connection between Maternal Employment and Childhood Obesity: Inspecting the Mechanism." Rev. Econ. Household 7:227-55.

Fitzpatrick, Maria Donovan. 2010. "Preschoolers Enrolled and Mothers at Work? The Effects of Universal Prekindergarten." J. Labor Econ. 28 (1): 51-85.

- 2012. "Revising our Thinking about the Relationship between Maternal Labor Supply and Preschool." J. Human Resources 47 (3): 583-612.

Foster, Gary D., Sandy Sherman, Kelly E. Borradaile, et al. 2008. "A Policy-Based School Intervention to Prevent Overweight and Obesity." Pediatrics 121 (4): e794-e802.

Fryar, Cheryl D., Margaret D. Carroll, and Cynthia L. Ogden. 2016. "Prevalence of Obesity among Children and Adolescents Aged 2-19 Years: United States, 1963-1965 through 2013-2014." Health E-Stats. Hyattsville, MD: Centers for Disease Control and Prevention. https://www.cdc.gov/nchs/data/hestat/obesity _child_13_14/obesity_child_13_14.pdf.

Gelbach, Jonah B. 2002. "Public Schooling for Young Children and Maternal Labor Supply." A.E.R. 92 (1): 307-22.

Goodman, Elizabeth, Beth R. Hinden, and Seema Khandelwal. 2000. "Accuracy of Teen and Parental Reports of Obesity and Body Mass Index." Pediatrics 106:52-58

Herbst, Chris, and Erdal Tekin. 2010. "Child Care Subsidies and Child Development." Econ. Educ. Rev. 29:618-38.

Kuczmarski, Marie F., Robert J. Kuczmarski, and Matthew Najjar. 2001. "Effects of Age on Validity of Self-Reported Height, Weight, and Body Mass Index: Findings from the Third National Health and Nutrition Examination Survey, 19881994." J. American Dietetic Assoc. 101:28-34.

Liu, Echu, Cheng Hsiao, Tomoya Matsumoto, and Shinyi Chou. 2009. "Maternal Full-Time Employment and Overweight Children: Parametric, Semi-Parametric, and Non-Parametric Assessment." J. Econometrics 152:61-69.

Lubotsky, Darren, and Javaeria A. Qureshi. 2018. "Assessing the Smooth Rise in Mothers' Employment as Children Age.” J. Human Capital 12 (4): 604-39.

Maher, Erin, Guanghui Li, Louise Carter, and Donna B. Johnson. 2008. "Preschool Child Care Participation and Obesity at the Start of Kindergarten." Pediatrics 122:322-30.

Miller, Daniel P. 2011. "Maternal Work and Child Overweight and Obesity: The Importance of Timing." J. Family and Econ. Issues 32:204-218.

Millimet, Daniel L., and Rusty Tchernis. 2015. "Persistence in Body Mass Index in a Recent Cohort of US Children." Econ. and Human Biology 17:157-76.

Morrill, Melinda S. 2011. "The Effects of Maternal Employment on the Health of School-Age Children." J. Health Econ. 30:240-57.

Morrissey, Taryn W. 2012. "Trajectories of Growth in Body Mass Index across Childhood: Associations with Maternal and Paternal Employment." Soc. Sci. and Medicine 95:60-68.

Morrissey, Taryn W., Rachel E. Dunifon, and Ariel Kalil. 2011. "Maternal Employment, Work Schedules, and Children's Body Mass Index." Child Development 82:66-81. 
National Center for Health Statistics. 2002. "2000 CDC Growth Charts for the United States: Methods and Development." Vital and Health Statistics, ser. 11, no. 246. Hyattsville, MD: Centers for Disease Control and Prevention. http:// www.cdc.gov/growthcharts/2000growthchart-us.pdf.

Robinson, P. M. 1988. "Root- $N$-Consistent Semiparametric Regression.” Econometrica 56:931-54.

Ruhm, Christopher J. 2008. "Maternal Employment and Adolescent Development." Labour Econ. 15:958-83.

Sawyer, Michael G., Taylor Harchak, Melissa Wake, and John Lynch. 2011. "FourYear Prospective Study of BMI and Mental Health Problems in Young Children." Pediatrics 128 (4): 677-84.

Singh, Gopal K., Michael D. Kogan, Peter C. van Dyck, and Mohammad Siahpush. 2008. "Racial/Ethnic, Socioeconomic, and Behavioral Determinants of Childhood and Adolescent Obesity in the United States: Analyzing Independent and Joint Associations." Ann. Epidemiology 18:682-95.

Story, Mary, Marilyn S. Nanney, and Marlene B. Schwartz. 2009. "Schools and Obesity Prevention: Creating School Environments and Policies to Promote Healthy Eating and Physical Activity." Milbank Q. 87: 71-100.

Tandon, Pooja S., Jeffrey Wright, Chuan Zhou, Cara Beth Rogers, and Dimitri A. Christakis. 2010. "Nutrition Menu Labeling May Lead to Lower-Calorie Restaurant Meal Choices for Children." Pediatrics 125:244-48.

Trasande, Leonardo, and Samprit Chatterjee. 2009. "The Impact of Obesity on Health Service Utilization and Costs in Childhood." Obesity 17:1749-54.

Trasande, Leonardo, Yinghua Liu, George Fryer, and Michael Weitzman. 2009. "Effects of Childhood Obesity on Hospital Care and Costs, 1999-2005." Health Affairs 28:w751-w760.

Verardi, Vincenzo, and Nicolas Debarsy. 2012. "Robinson's Square Root of NConsistent Semiparametric Regression Estimator in Stata.” Stata J. 12:726-35.

Ziol-Guest, Kathleen M., Rachel E. Dunifon, and Ariel Kalil. 2013. "Parental Employment and Children's Body Weight: Mothers, Others, and Mechanisms." Soc. Sci. and Medicine 95:52-59. 